\title{
A responsabilidade social e a afirmação da alteridade: o novo humanismo da ética de Emmanuel Lévinas*
}

\section{Social responsibility and the affirmation of alterity: the new humanism of the Emmanuel Lévinas's ethics}

Rudhra Gallina'

\section{Resumo}

Este artigo pretende articular a compreensão do sentido metafísico que Lévinas dá à ética, reconhecendo sua herança de pensamento na ontologia hedeggeriana. Acompanhamos a discussão sobre como a morte do outro é o ponto em que restituímos o caráter ético para o sentido, para além da finitude da "minha" morte como momento ontológico da existencialidade do “dasein", na noção de infinito no rosto do outro. Ao final da reflexão, chegamos à consideração do nascimento da ética com a chegada do "terceiro", no qual a justiça rompe com a violência do amor de que brota. Nosso objetivo foi o de reconhecer o sentido humano fundado na alteridade como aquilo que possibilita a experiência e a contextualização humana.

Palavras-chave: Responsabilidade. Alteridade.Humanismo.

\begin{abstract}
The aim of this paper is to articulate the understanding of the metaphysical sense that Lévinas gives to ethics, by recognizing what he inherited from the thinking of heideggerian ontology. We have surveyed the discussion about how the death of the other is the point at which we give back the ethical character to meaning, beyond the finitude of "my" death as the ontological moment of the existentiality of "dasein", in the notion of the infinite in the face of the other. At the end of this reflection, we arrive at the consideration of the birth of ethics with the arrival of a "third", in which justice breaks with the violence of the love from which it stems. Our objective was to recognize human meaning as founded on alterity as that which make human experience and contextualization possible.
\end{abstract}

Keywords: Responsibility. Alterity.Humanism. 


\section{Introdução}

"Responsabilidade" é um tema que toca os fundamentos da nossa vida social e, justamente por isso, costuma aparecer como algo que se assume a partir de uma suposta evidência, ou seja: todos nós nos orientamos no mundo social supondo saber o que significa ser responsável. Entretanto, sabemos como as evidências, principalmente no que diz respeito aos princípios e fundamentos, devem ser questionadas, pois acabam assumindo a função de sustentar um saber vago e mediando, contribuindo para a mera manutenção do "edifício" do ordenamento social. Assim, quando buscamos avaliar o caráter desse "edifício", questionando suas disposições, seus resultados e implicações, precisamos nos aprofundar na análise de seus fundamentos. Assim, tratar-se-á aqui de questionar qual o fundamento da "responsabilidade social", uma vez que ela é uma das bases mais importantes de nossa orientação social. Nisso, estaremos nos envolvendo com o que caracteriza tipicamente a reflexão filosófica.

Várias são as contribuições de filósofos e doutrinadores para pensar a questão, sendo essa diversidade articulada pelos diversos contextos em que esses pensadores estão comprometidos. No que diz respeito a tais contextos, podemos distinguir, de modo geral, dos tipos antagônicos. Um que envolve a concepção de que a responsabilidade precisa do pressuposto da ordem para ser possível, e outro que entende justamente a necessidade de questionar e desconstruir a ordem para se estabelecer. Nos dois sentidos, a palavra "responsabilidade" significa coisas diferentes. No primeiro, entende-se que seria vigilância para manutenção da ordem; e no segundo, impõese na urgência de um cuidado e atenção constantes diante do caos social.

No fundo dessas concepções, encontramos as duas maneiras assumidas na tradição do pensamento ocidental para caracterizar a estrutura ontológica do mundo. Na primeira, a ordem, seja pensada como natural ou positivada, deve se estabelecer em consonância com o movimento estático dos processos históricos, como encontramos em ideologias positivistas, por exemplo, que privilegiam o movimento estático em detrimento do dinâmico. Na segunda, a "ordem" implica num estado de perpétua tensão projetada numa temporalidade voltada para o futuro, assumindo a dinamicidade e o conflito como os fatores que mobilizam o processo. Por um lado, mento. Por outro, o fundamento só pode se dar, se houver tensão entre ordem e desordem, assim como a consciência da justiça que se dá pela sensibilização da injustiça social, e não por princípios normativos ou ideais.

Neste breve trabalho de reflexão, procuraremos questionar a primeira proposta de compreensão da responsabilidade, reconhecendo mais a fundo pela desconstrução, os pressupostos que podem nos instalar na segunda proposta. Encontramos essa discussão nos meios acadêmicos atuais de pesquisa sob o marco de orientação pós-moderna contra a estrutura do pensamento moderno.

\section{Modernidade e violência}

O pensamento moderno está orientado pela identificação: conhecer é identificar. O conhecimento reconduz o objeto desconhecido às estruturas da identificação com a subjetividade: verdade como adaequatio. De fato, até a modernidade, seinterpreta o trabalho do pensamento filosófico como um esforço que conduz a diversidade e a multiplicidade dos entes a uma noção de unidadetotalidade, seja ela a "água” em Tales de Mileto, a ideia de “Bem” em Platão, o conceito de "ser" em Aristóteles, ou "Deus" na Filosofia medieval. Temos assim, certo "sentimento" de que estamos conhecendo algo, pois podemos exercer um controle sobre o objeto visado: uma relação de poder. Isso aparece de modo explícito na modernidade com seus imperativos de assenhoramento da natureza, já enunciados nos escritos de Bacon, mas também percebemos que essa articulação aparece em certos antecedentes na Antiguidade e na Idade Média. De toda maneira, a mesma estrutura parece se reproduzir, seja na metafísica do ser, ou na transcendentalidade do sujeito autônomo de Kant, dominando o que podemos chamar de corrente central do pensamento ocidental.

A certeza, que antes provinha de um encontro objetivo com o mundo, mesmo que na contemplação da objetividade do "mundo das ideias", Descartes vai encontrar, lançando os pressupostos que vão orientar o pensamento moderno, no próprio “eu”. É a autoconsciência a premissa que estabelece as referências para a inteligibilidade. No interior do "eu" é colocada a pedra fundamental que edificará a nova compreensão que o homem moderno começa a construir do mundo e de si mesmo: "eu penso, logo sou". 
Como consequência disso, temos essa estrutura moderna da compreensão que não consegue compreender nada além do que ela mesma é capaz de estruturar, isto é, sua própria constituição como "mesmo", o objeto constituído pelo sujeito. Ficamos assim, presos no solipsismo da ideia de sujeito. Em tudo que se compreende, ele se afirma a si mesmo, deixando sua marca de apropriação nas formas de um saber objetificante, que se impõe violentando a alteridade daquilo que lhe difere. Essa violência se manifesta na própria estruturação transcendental da subjetividade como modelo da compreensão que antevê as possibilidades em seu apriorismo. O "outro" só é visto como "outro" do "mesmo", isto é, um "outro" como "eu". Essa metafísica moderna da subjetividade estabelece a precedência da identidade sobre a diferença, pois é somente na identificação que compreendemos o que nos vem ao encontro. Reconduzimos o desconhecido ao conhecido pelas formas da identidade, afastando-nos daquilo que não compreendemos, amedrontados por não conseguirmos exercer controle sobre o desconhecido, num mundo onde o medo nos faz seres, cada vez mais, espontaneamente violentos.

A violência em que nos acostumamos quando estamos condicionados à compreensão que se apoia nessa metafísica, que podemos chamar de ontologia da identidade, desemboca no totalitarismo que se articula numa inércia política e burocrática apoiada nessa compreensão. Daí a necessidade de se repensarem os pressupostos éticos para libertarmo-nos dessa articulação inconsciente entre ontologia e política.

A pergunta que se coloca então para a pós-modernidade é a seguinte: podemos superar a estrutura transcendental da subjetividade para encontrarmos no mundo algo além do que as referências do sujeito são capazes de nos proporcionar? ${ }^{2}$ De certo modo, parece que a intenção do esforço fenomenológico vai nesse sentido quando afirma: "às coisas em si mesmas" ${ }^{3}$ Poderíamos dizer que, pela fenomenologia, começamos, ainda que de maneira incipiente, a estruturar nossa preocupação pelo "outro" enquanto tal, no esforço de desenvolver uma experiência da compreensão que não se dê pela repetição do "mesmo". O filósofo lituano-francês, Emmanuel Lévinas, em um dos primeiros artigos publicados na França sobre Ser e Tem-

\footnotetext{
2 MILOVIC, M. Comunidade da diferença. Rio de Janeiro: Relume Dumará, 2004. p. 81.

3 HEIDEGGER, M. Ser e tempo. Petrópolis: Vozes, 1993. p. 57.
}

po de Heidegger, em 1932, Descobrindo a existência com Husserl e Heidegger, nos diz como a fenomenologia aparece como um caminho para se pensar a possibilidade da liberdade, na medida em que ela desconstrói a rigidez da subordinação totalitária do objeto ao sujeito.

A partir daí, o trabalho de Lévinas se desenvolverá na busca em fundamentar uma responsabilidade ética que fosse mais fundamental do que a responsabilidade pelo ser, típica da ontologia. A função dessa responsabilidade, em sua configuração ética, deveria ser a de abrir a possibilidade para ultrapassar as categorias da tradição e nos libertar da lógica da identidade em que sempre se reproduz o "mesmo", violentando o "outro". Orientado pela alteridade, o sentido se manifestaria numa revolução do "eu", num chamado para uma responsabilização ética, uma invocação à humildade que produz essa reviravolta no "eu", dando-lhe assim sua identidade sempre subordinada àquilo que lhe difere, isto é, que nunca se fecha numa totalidade em si e, assim, mantém-se numa atenção que não só dignificaria o pensamento, mas o tornaria propriamente pensante.

\section{0 pensamento de Emmanuel Lévinas}

É nesse sentido que Lévinas se vale da ontologia fenomenológica de Ser e Tempo para radicalizá-la na tentativa de responder com a urgência exigida à interpelação da alteridade do "outro". Consciência surgindo como responsabilidade. Em Heidegger, há um aceno a essa nova abertura ética, quando se entende a compreensão como uma atitude, um modo de ser do dasein, que, sendo seu privilégio pré-ontológico, na chamada "pré-compreensão", já é sempre pressuposta em todo relacionamento que venhamos a estabelecer com algum ente intramundano como o próprio fato da existência ("facticidade"). Nossa responsabilidade acontece como projeto ontológico e não podemos nos esquivar disso. ${ }^{4}$

\footnotetext{
4 A inevitabilidade de assumir a responsabilidade por nossa existência aparece em Heidegger no caráter da "facticidade", e é já um passo para uma consideração ética do pensamento, mas ainda não é uma responsabilidade ética radical com a existência do outro. Pois tanto no privilégio pré-ontológico (inautêntico) da pré-compreensão, como na estrutura propriamente ontológica (autentica), aberta pela angústia do ser-para-morte, o dasein permanece como um ente voltado para seu ser, em que encontrar o sentido desse ser acontece egoisticamente, num faceaface com sua própria finitude, sua mortalidade.
} 
Contra o pensamento controlador que sempre sucumbe à tentação de antever as possibilidades para desenvolver um "caminho seguro", percebemos que não podemos nos esquivar de ter de aceitar certo risco, pois nunca podemos prever todas as consequências e implicações de nossas atitudes, o que nos faz ter de assumir nossa responsabilidade "para além de nossas intenções". ${ }^{5}$ Para Lévinas, trata-se até mesmo de uma responsabilidade que deve assumir a assimetria social como sua (in)condição, sem esperar reciprocidade. Isto é, seríamos responsáveis até mesmo pela responsabilidade do "outro", sem esperar que ele seja responsável por si. O que nos permitiria falar de responsabilidade pelo outro como acolhimento incondicional, desenvolvendo uma perspectiva teórica capaz de orientar nossa conduta com os entes mais vulneráveis em nossas sociedades.

Talvez tenhamos que considerar que, somente uma responsabilidade afirmativa, como essa proposta por Lévinas, poderia nos tirar das amarras dialéticas que mesmificam nossos sistemas de relações, reduzindo as possibilidades de interpretação à estrutura bipolar da relação "causa-efeito", que acaba recriminando atitudes, isolando-as dos contextos mais gerais, culpando infratores e criminosos como se não houvesse uma responsabilidade de toda sociedade frente às atitudes individuais, que, dessa maneira, continuarão gerando outras idênticas, numa estrutura transgeracional que faz com que as gerações venham sempre reproduzindo as configurações em que estão atoladas as gerações anteriores.

Apesar dessa forma de encarar a responsabilidade não ser nova, ainda parece difícil para o indivíduo, "bom cidadão", que se satisfaz em cumprir formalmente suas obrigações legais perante o Estado, considerandose assim um ser integro e completo, características que sustentam a autocompreensão de seu ser como uma unidade-totalidade, sentir que também é responsável pelos delitos de um infrator. Que ao ser responsável pelo "outro", também é responsável pelas condições em que ele se encontra, uma vez que somos, antes de sermos indivíduos singulares, numa suposta unidade-totalidade de nosso ser individual, seres em relação na pluralidade humana, estando nossa integridade e (im)possível completude referidas à nossa relação com o "outro".
O peso que a palavra "responsabilidade" carrega está associado à interpretação moral que a conota como "culpa", fundamentada nessa compreensão da pseudo-autossuficiência do indivíduo como uma unidade-totalidade. Mas essa interpretação pode ser desfeita se passarmos a fundamentar a compreensão que temos da humanidade do indivíduo na pluralidade das relações inter-humanas, no lugar dessa concepção do humano como um sujeito autônomo. O indivíduo particular é sempre "parte" e nunca pode ser tomado por uma totalidade, como nos diz Lévinas no início de seu ensaio intitulado $O$ eu e a totalidade, pois apenas assim ele pode pensar sensivelmente, assumindo sua responsabilidade ética.

\begin{abstract}
O pensamento começa, precisamente, quando a consciência se torna consciência de sua particularidade, ou seja, quando concebe a exterioridade para além de sua natureza de vivente, que contém; quando ela se torna consciência de si ao mesmo tempo que consciência da exterioridade que ultrapassa sua natureza, quando ela se torna metafísica. ${ }^{6}$
\end{abstract}

Segundo Lévinas, essa exterioridade impõe ao "eu" a responsabilidade pelo "outro", sendo ela, uma responsabilidade pela alteridade do outro, isto é, por aquilo que difere, que sempre nos escapa, que deixa apenas vestígios, aquilo que é absolutamente diferente, não num sentido de qualitativo, mas substantivo: o fato de que o outro é outro, por mais que possa apresentar similaridade. Assim, Lévinas caracteriza essa responsabilidade como sendo, fundamentalmente, responsabilidade pela morte do outro. A alteridade aparece aqui como a própria morte do outro, aparece na vulnerabilidade da exposição do seu rosto, como manifestação inaugural que abre o sentido ético. Neste, nos espantamos com uma nudez, com uma fragilidade, com uma indigência que nos convoca à humildade.

A morte do outro homem me concerne e me questiona como se eu me tornasse, por minha eventual indiferença, o cúmplice desta morte invisível ao outro que aí se expõe; e como se, antes de ser eu mesmo voltado a ele, tivesse que responder por esta morte do outro e não deixar outrem só, em sua solidão mortal. [...] A morte significa na concretude do que é para mim o impossível abandono de outrem à sua solidão, na proibição deste abandono dirigido a mim. Seu sentido começa no inter-humano. ${ }^{7}$ 
Indicando sua morte, o rosto é assim uma "não resposta" do outro que nos faz insubstituíveis, únicos, na tarefa de responder por ele, responsabilizando-nos por ele, acolhendo-o. Nessa responsabilidade, não se trata de assimilar, ou de saber algo a cerca do outro, pois a alteridade é infinita, inassimilável e inabarcável. A relação com esse infinito é de caráter inaugural e se dá pelo acolhimento, uma vez que se manifesta sempre como um primeiro dizer, inaugurador da linguagem e ao qual se subordina o sentido de tudo que pode ser dito e comunicado: o fato de que a linguagem e a comunicação só se estabelecem como possibilidades abertas a partir da relação intersubjetiva entre o "eu" e o "outro".

Podemos entender que Lévinas, ao se remeter à famosa fala de um dos personagens de Dostoievski, que expressa o sentido assimétrico da ética ao dizer: "somos todos culpados de tudo e de todos, e eu mais que todos os outros", está se referindo à situação excepcional do "eu", entendido como totalidade, e não ao indivíduo sensível e consciente de sua particularidade, articulação de sua alteridade. Sinal disso aparece quando ele acrescenta o cuidado com o "terceiro", em que se abre a noção de justiça, para além da relação entre o "eu" e o "outro" e seus apelos éticos. Com isso, poderíamos abordar as questões da vida política, remetendo-nos à interpretação ética do que está fundamentalmente em jogo no convívio social: a responsabilidade que temos pela mortalidade do outro, para além da relação face a face, porém, ainda apoiada na estrutura transcendental dessa separação entre o "eu” e o "outro", que possibilita a relação responsável com a alteridade.

\section{0 "terceiro"}

Na ética de Lévinas, o "terceiro" surge como uma figura privilegiada para pensar o outro, pois em toda relação com o outro, sempre estamos em relação com um terceiro, viabilizando com isso uma implicação política em que a justiça não haveria sem a ética, e vice-versa. Nessa relação com o terceiro, está delineado o que provoca em nós o movimento de consciência, requisito necessário para estabelecer a decisão que limita o relacionamento face a face, a partir da necessidade de se pensar a igualdade de direitos.

O termo "justiça", com efeito, situa-se bem melhor lá onde se requer a "equidade" e não minha "subordinação" a outrem. Se é mister a equidade, requer-se a comparação e a igualdade: igualdade entre o que não se compara. Consequentemente, o termo "justiça" aplica-se muito mais à relação com o terceiro do que à relação com outrem. Mas, na realidade, a relação com outrem nunca é só relação com outrem: desde já o terceiro está representado em outrem; na própria aparição do outro o terceiro já está a me olhar. Isto faz com que a relação entre a responsabilidade para com outrem e a justiça seja extremamente estreita. ${ }^{8}$

Temos com isso a medida de uma referência para pensar a instituição política da justiça a partir da resistência contra a violência do outro a um terceiro: violência medida contra a violência do outro. A instituição não pode edificar-se no pressuposto ontológico de que possa existir uma justiça não violenta no nível da política, mas sim, com sinceridade, defender que uma violência pode ser mais justa do que outra, e que o amor não se resumiria apenas na aceitação incondicional, que pode gerar essa sensação de dissimulada de abandono em uma criança, por exemplo, mas construção de limites, como os que um filho precisa obter de um pai para construir sua identidade. A sociedade entre os homens deve se instituir diante da justiça, na qual o respeito não é apenas submeter-se à lei, mas a um ser que me ordena uma responsabilidade, $o$ que acontece por meio de uma violência menor que me faz refém dessa situação coletiva.

Entretanto, essa violência menor não estaria por isso legitimando a violência, mas apenas algum tipo de violência necessária. Lévinas nos indica que ela deve sempre ser evitada, na medida do possível. É aí que a filosofia se torna sabedoria do amor. Nesse sentido, trata-se de construir uma relação com os limites que tenha por objetivo o cuidado e a atenção com o outro, e que certa violência intrínseca à condição da relação nunca perca de vista esse cuidado, orientando-se fundamentalmente pela alteridade do próximo que, na figura do terceiro, também é próximo do próximo.

Diante dessa responsabilidade ética de justiça do ser, a questão ontológica mais fundamental já não pode ser como pensa Heidegger, retomando o questionamento metafísico de Leibniz: "por que há o ser e não antes o nada?"; nem ainda a de Kant como orientação da Crítica da Razão Prática: “que devo eu fazer?”; mas, em relação à alteridade do outro, perguntar: "tenho direito de ser?".

8 LÉVINAS, E. De Deus que vem a ideia. Petrópolis: Vozes, 2002. p. 119. 
Questão de sentido que não se volta para nenhuma finalidade natural, mas que se perpetua em nossos estranhos discursos humanos sobre o sentido da vida, em que a vida se desperta à humanidade. ${ }^{9}$

\section{Conclusão}

A injustiça estruturada pela história de dominação das ideologias políticas totalitárias, gestada pela metafísica da identidade, que subjuga tudo e todos que se encontrem sob a marca do "outro", do "diferente", do "estrangeiro", do "emigrado", do "apátrida”, do "marginalizado", da "periferia", precisa ser respondida com urgência. Não podemos esperar soluções discursivas, racionalizadas, ou mesmo mediadas por alguma dialética, que pretendam estruturar novamente formas do ordenamento do "outro" sob o "mesmo", como, por exemplo, na teoria de Habermas do "agir comunicativo" em seu pressuposto de que a linguagem, para respeitar a "diferença" do outro, deve se apoiar na reciprocidade de uma racionalidade transcendental da comunicação, entendendo o dissenso apenas como um obstáculo temporário a ser superado para que se atinja o sentido democrático das relações, no lugar de entendê-lo como uma condição primeira.

Lévinas não quer abordar a ética pela racionalidade, mas pela sensibilidade, uma vez que o que parece se esconder por traz da necessidade de racionalizar é o exercício do poder, como já denunciava Nietzsche. Ele nos diz, concluindo um de seus ensaios ( $A$ ontologia é fundamental?), que o ser humano só aparece numa relação que não é poder.

Assim, ele irá pensar as condições para que a fenomenologia esteja relacionada diretamente com a ética e não antes com a ontologia. Sensibilização como atitude que não se alimenta do apoderamento da compreensão racional, já que a razão tende sempre a anular o valor dos sentidos, mas esforço corajoso do encontro com aquilo que não pode ser compreendido, mas que é sempre motivo que desperta nossa "a-tenção", num certo tipo de "empirismo radical", resgatando o valor do "estranhamento", que sempre foi a porta de entrada para a filosofia: saída de si como a aproximação do próximo, transcendência como proximidade, proximidade como responsabilidade pelo outro, transcendência como comunicação implicando o "dom", "a casa aberta". ${ }^{10}$

Buscamos, junto com essa proposta ética de Lévinas, a possibilidade de pensar o humano que não reduza seu acontecimento às formas da subjetividade, mas que afirme os seres humanos enquanto tais, em sua pluralidade e alteridade como o valor primeiro: Humanismo do outro homem. Radicalmente falando, seria preciso aceitar incondicionalmente a possibilidade de estabelecer uma relação com o "outro" em sua incompreensão, para que a responsabilidade atinja seu alcance ético, liberando as possibilidades para o encontro com a alteridade absoluta. Com isso, estaríamos falando de uma precedência da alteridade sobre a identidade, da diferença sobre a igualdade. Essa disposição não pode nunca ser preparada pela linguagem, ou pelo pensamento, pois é a própria vertigem da linguagem e do pensamento, onde eles encontram sua origem. Como se pensamento e linguagem fossem sempre o discurso que se origina e permanece no ambiente do "mesmo", quando assumidos como ponto de partida originário, isto é, não estabelecem a rigor uma relação. A separação radical da consideração da alteridade como ponto fundamental na assunção ética e humana, possibilitaria assim, não o estranhamento ético, mas o estranhamento do pensamento que possibilitaria a abertura do encontro com o rosto que se aproxima, isto é, a possibilidade do amor, paradoxalmente se funda na desigualdade, na separação, na alteridade, para que ele se realize de fato no mundo em que ainda podemos ter esperança de um porvir não reduzido à morte como aniquilamento. Não é encontro com um "horizonte de possibilidades", mas encontro vertical com a proximidade da distância infinita do "rosto do outro". Responsabilidade antes da consciência.

Assim, nossa busca não seria a de tornarmo-nos responsáveis, pois isso nós já sempre somos, mesmo quando não estamos conscientes disso. Nossa busca seria a de desenvolver pela sensibilidade, uma forma de sermos conscientes das implicações de nossa responsabilidade com o "outro" que se aproxima como pensamento originário. Sensibilização que estrutura nossa consciência, como atividade orientada pelo cuidado incondicional com o outro, o que pode vir a contribuir para as atividades que lidam diretamente com o cuidado "humanizado" da
10 LÉVINAS, E. De Deus que vem a ideia. Petrópolis: Vozes, 2002. p. 32. 
pessoa humana, notadamente entre profissionais da saúde, da educação e do serviço social, que têm fundamentalmente no humano seu substrato e objetivo. Mas também para pensar a urgente questão social dos refugiados, sem-terra, sem-teto, moradores de rua, desabrigados, apátridas, imigrantes, nas feridas internacionais abertas pelo colonialismo e que supuram nos guetos das metrópoles.

\section{Referências}

ARENDT, H. A condição humana. Rio de Janeiro: Forense Universitária, 2000.

BOURDIEU, P. A ontologia política de Martin Heidegger. Campinas: Papirus, 1989.

DERRIDA, J. Adeus a Emmanuel Lévinas. São Paulo: Perspectiva, 1997.

DERRIDA, J. Força da lei. São Paulo: Martins Fontes, 2007.

DERRIDA, J; DUFOURMANTELLE, A. Da hospitalidade. São Paulo: Escuta, 2003.

HABERMAS, J. O discurso filosófico da modernidade. São Paulo: Martins Fontes, 2000.

HADDOCK-LOBO, R. Da existência ao infinito: ensaios sobre Emmanuel Lévinas. Rio de Janeiro: PUC-Rio, 2006.
HEIDEGGER, M. Ser e tempo. Petrópolis: Vozes, 1993.

HEIDEGGER, M. Sobre o humanismo. Rio de Janeiro: Tempo Brasileiro, 1995.

KANT, I. Crítica da razão pura. São Paulo: Nova Cultural, 1996.

LÉVINAS, E. Crítica da razão prática. São Paulo: Martins Fontes, 2002.

LÉVINAS, E. De Deus que vem a ideia. Petrópolis: Vozes, 2002.

LÉVINAS, E. Deus, a morte e o tempo. Coimbra: Livraria Almedina, 2003.

LÉVINAS, E. Entre nós. Petrópolis: Vozes, 1997.

LÉVINAS, E. Fundamentação da metafísica dos costumes. São Paulo: Martin Claret, 2005.

LÉVINAS, E. Humanismo do outro homem. Petrópolis: Vozes, 1993.

LÉVINAS, E. Totalidade e infinito. Lisboa: Edições 70, 1980.

LOPARIC, Z. Ética e finitude. São Paulo: Escuta, 2004.

MILOVIC, M. Comunidade da diferença. Rio de Janeiro: Relume Dumará, 2004. 


\section{Para publicar na revista Universitas/JUS, acesse $o$ endereço eletrônico www.publicacoesacademicas.uniceub.br.}

Observe as normas de publicação, para facilitar e agilizar o trabalho de edição. 